\title{
What is the best Rocker Shoe design?
}

\author{
Jonathan Chapman ${ }^{1 *}$, Stephen Preece ${ }^{1}$, Christopher Nester ${ }^{1}$, Bjoern Braunstein ${ }^{2}$, Angela Höhne ${ }^{2}$,
} Gert-Peter Brüggermann²

From 3rd Congress of the International Foot and Ankle Biomechanics Community

Sydney, Australia. 11-13 April 2012

\section{Background}

Rocker shoes are often prescribed to reduce in-shoe pressures in order to minimise the risk of ulceration in diabetic patients. However, the efficacy of the 3 principal design features of a rocker shoe (apex position, rocker angle and apex angle, see Figure 1) is unknown. Only one known study to date has systematically varied 2 of the 3 design features [1]. Therefore the aim of this study was to investigate the effect of the three principal design features, quantify inter subject variability and establish whether there is any difference in the response of the diabetic and the healthy cohort by recording in shoe plantar pressure.

\section{Materials and methods}

By using 12 different rocker shoe designs and a control shoe, we systematically varied each design feature apex position (50-70\% of shoe length), rocker angle (10-30 $\left.{ }^{\circ}\right)$

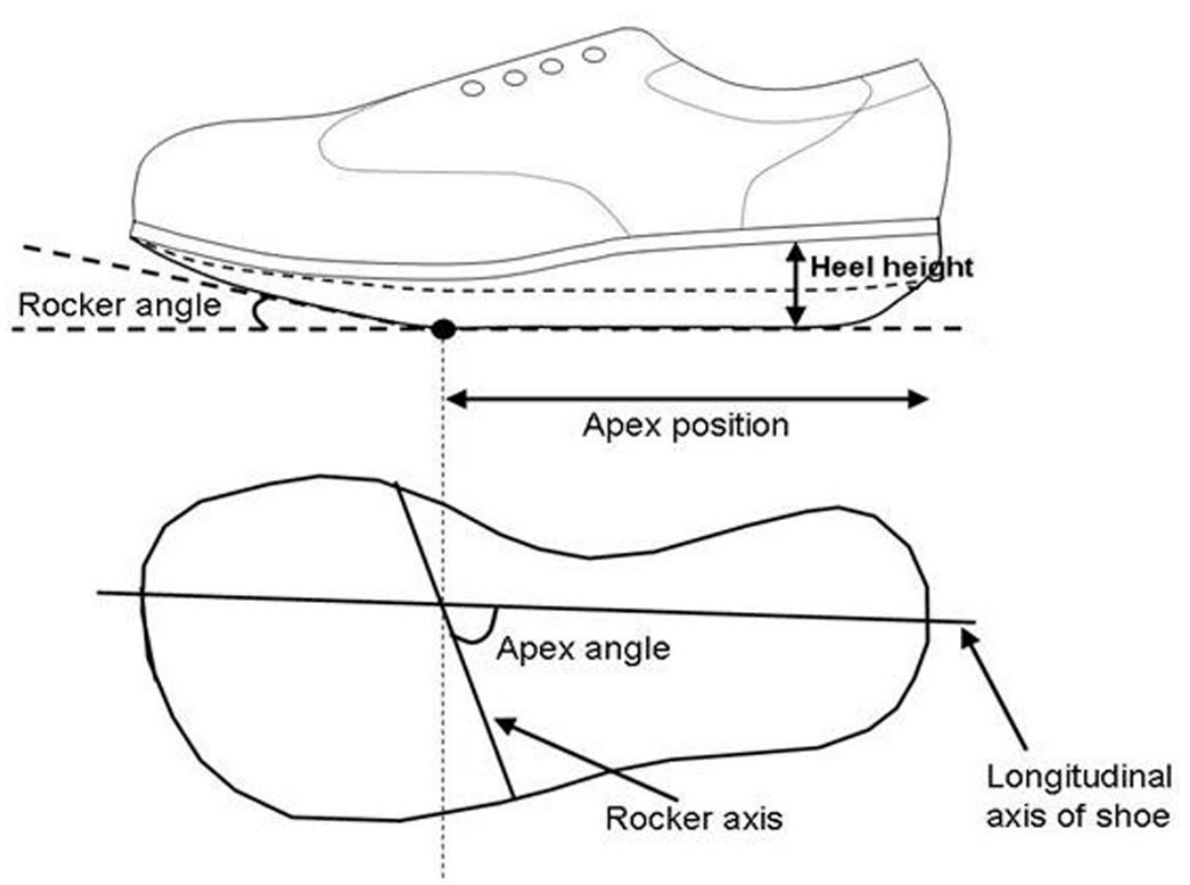

Figure 1 Apex position, rocker angle and apex angle in a rocker shoe

* Correspondence: j.d.chapman@edu.salford.ac.uk

'School of Health, Sport and Rehabilitation Sciences, University of Salford, UK

Full list of author information is available at the end of the article 
and apex angle (70-100 to longitudinal shoe axis). For each shoe, peak 1st metatarsophalangeal joint (MPJ) pressure was measured during walking. Data was collected from 30 diabetic and 30 healthy subjects and repeated measures ANOVA used to investigate the mean effect of each feature. Descriptive statistics were used to investigate inter-subject variability and a twoway ANOVA was used to compare the response between the diabetic and healthy cohort.

\section{Results}

All three design features had a significant effect on peak 1st MPJ pressure. However, there was considerable inter-subject variability in the optimal rocker angle and optimal apex position. In contrast, an apex angle of between $90-100^{\circ}$ resulted in minimal pressures across almost all subjects.

\section{Conclusion}

The results suggest that pressure offloading can be achieved by employing an apex angle of approximately $95^{\circ}$. However, rocker angle and apex position should be chosen on individual by individual basis.

\section{Acknowledgments}

The research leading to these results has received funding from the European Community's Seventh Framework Programme ([FP7/2007-2013] [FP7/2007-2011]) under grant agreement n [NMP2-SE-2009-229261].

\section{Author details}

'School of Health, Sport and Rehabilitation Sciences, University of Salford, UK. ${ }^{2}$ Institute of Biomechanics and Orthopaedics, German Sport University, Cologne, Germany.

Published: 10 April 2012

\section{Reference}

1. Van Schie $C$, et al: Design criteria for rigid rocker shoes. Foot Ankle Int 2000, 21:833-844.

\section{doi:10.1186/1757-1146-5-S1-O6}

Cite this article as: Chapman et al.: What is the best Rocker Shoe design? Journal of Foot and Ankle Research 2012 5(Suppl 1):O6.

\section{Submit your next manuscript to BioMed Central} and take full advantage of:

- Convenient online submission

- Thorough peer review

- No space constraints or color figure charges

- Immediate publication on acceptance

- Inclusion in PubMed, CAS, Scopus and Google Scholar

- Research which is freely available for redistribution

Submit your manuscript at www.biomedcentral.com/submit 